\title{
Morfologia Floral de uma População de Tucumã, Astrocaryum aculeatum G. Mey. (Arecaceae) na Amazônia Central
}

\author{
Christinny Giselly BACELAR-LIMA², Maria Silvia de MENDONÇA², Tereza Cristina T. S. BARBOSA ${ }^{3}$ \\ RESUMO \\ Foi realizada a descrição morfológica das inflorescências, bem como das flores pistiladas e estaminadas, de uma população de \\ Astrocaryum aculeatum Meyer, no Campus do Instituto Nacional de Pesquisas da Amazônia - INPA. A inflorescência é do tipo \\ panícula de espigas, pedunculada, interfoliar e apresenta tamanho médio de $146 \pm 20,3 \mathrm{~cm}$. Uma bráctea lenhosa provida de \\ espinhos em toda superfície externa protege a inflorescência. Estas apresentam cerca de $375 \pm 49,5$ ráquilas. Foi estimado de 500 a \\ 1.200 flores pistiladas e 190.000 a 260.000 flores estaminadas por inflorescência. As flores estaminadas apresentam um padrão de \\ cores que variam do vinho ao creme e também com tons mesclados de vinho e creme.
}

PALAVRAS-CHAVE

Morfologia floral, Astrocaryum aculeatum, Palmeira, Amazonas.

\section{Floral morphology of one population of Astrocaryum aculeatum G. Mey. (Arecaceae) in the CentralAmazon-Brazil}

\begin{abstract}
Morphological descriptions are provided for inflorescences of pistillate and staminate flowers of a population of Astrocaryum aculeatum Meyer located on the campus of the Instituto Nacional de Pesquisas da Amazônia (INPA). The inflorescence is an interfoliar, panicle of spikelets, with a peduncle, and medium size of $146 \pm 20.3 \mathrm{~cm}$ in length. Woody, thorny bracts are present on the entire external surface, protecting the inflorescence. Each inflorescence had approximately $375 \pm 49.5$ rachillae. Each inflorescence was estimated to have about 500 to 1.200 pistillate flowers and 190.000 to 260.000 staminate flowers. Staminate flowers varied in colouration from wine to cream and intermediate mixes of wine and cream.
\end{abstract}

KEYWORDS

Floral Morphology, Astrocaryum aculeatum, Palm, Amazonas.

${ }^{1}$ Instituto Nacional de Pesquisas da Amazônia/INPA - Coordenação de Pesquisas em Botânica/CPBO. Av. André Araújo 2936, Bairro Petrópolis, Manaus-Amazonas Caixa Postal 478, CEP 69.083-000 - Brasil. Fone: Fone: (092) 3643-3119/9951-1402. E-mail: christinnyg@yahoo.com.br

2, 3 Universidade Federal do Amazonas/UFAM - Laboratório de Botânica Agroflorestal/LABAF. Mini Campus, Bloco G. Rua Gal. Rodrigo Otávio Jordão Ramos, 3000 , Aleixo. CEP 69077-000, Manaus-Amazonas, Brasil. Fax: (092) 644-2354. 


\section{INTRODUÇÃO}

As palmeiras (Arecaceae) são as plantas mais características da flora tropical (Uhl \& Dransfield, 1987), constituindo um dos grupos ecologicamente mais importantes dentre as plantas, tendo praticamente todas as partes aproveitadas, desde a alimentação até o uso medicinal. Os frutos e sementes são utilizados na alimentação do homem e de animais e as folhas e estipes na construção de casas (cobertura, assoalho e parede) pelas populaçôes do interior da Amazônia (Mendonça \& Araújo, 1999; Miranda et al., 2001).

Algumas das palmeiras neotropicais mais espinhosas pertencem ao gênero Astrocaryum e possuem espinhos pretos, afiados, com $30 \mathrm{~cm}$ de comprimento cobrindo o estipe, os quais são altos, algumas vezes pequenos e subterrâneos, solitários ou em grupo. As folhas são pinadas, em número de três a 30, espinhosas com a superfície abaxial esbranquiçada, o que o diferencia do gênero Bactris. As ráquilas são numerosas, suportando flores unissexuadas (Henderson et al., 1995).

O gênero em questão compreende 24 espécies amazônicas, das quais cinco pertencem ao subgênero Pleiogynanthus e 19 ao subgênero Monogynanthus. O primeiro, é definido pela presença de várias flores pistiladas na base da ráquila, com fruto de pericarpo liso e com folhas apresentando pinas orientadas em várias direçōes (com exceção da espécie colombiana Astrocaryum malybo H. Karst). O subgênero Monogynanthus é definido pela presença de uma única flor pistilada na base da ráquila, com fruto de pericarpo espinhoso e com folhas de pina regularmente arranjadas em um plano (exceto para Astrocaryum alatum H. F. Loomis, espécie da Costa Rica). Este subgênero é, por sua vez, subdividido nas secções Munbaca e Ayri, que podem ser distinguidas pela posição pêndula ou ereta da inflorescência (Khan \& Millán, 1992).

A. aculeatum, inserida no subgênero Pleiogynanthus (Kahn \& Millán, 1992), é uma palmeira comumente encontrada em pequenas densidades no interior da floresta e, em maior número, nas áreas abertas, seguindo principalmente a ocupação humana (Cavalcante, 1991). Como ilustrada na figura 1a, é uma espécie solitária, monóica, com estipe ereto, alcançando de 8 a $20 \mathrm{~m}$ de altura (Henderson et al., 1995). No Brasil, é freqüentemente encontrada nos estados do Amazonas, Pará, Roraima, Rondônia e Acre, distribuindo-se também pelas Guianas, Peru e Colômbia (Henderson, 1995; Lorenzi et al., 1996 e 2004; Cavalcante, 1991; Miranda et al., 2001). Seus frutos são ricos em próvitamina A (Mendonça \& Araújo, 1999), sendo a polpa muito apreciada pela população do Amazonas como recheio de sanduíches e tapiocas. As fibras das folhas e o estipe são usados para confecção de artesanatos e utensílios como redes, cordas e arcos.

A descrição da morfologia floral permitirá melhor conhecimento da espécie, contribuindo para estudos da sua biologia reprodutiva.

\section{MATERIAL E MÉTODOS}

O estudo foi desenvolvido no Campus do Instituto Nacional de Pesquisas da Amazônia - INPA, localizado no município de Manaus, Amazonas, Brasil (03 05.730' S, 59 $\left.59.183^{\prime} \mathrm{W}\right)$, que tem uma área de aproximadamente 14 ha, com vegetação de floresta secundária (Gentry, 1978; Prance, 1975).

O clima do local é caracterizado como "Afi" na classificação de Köpen, com pluviosidade e temperatura média anual de 2.458 $\mathrm{mm}$ e $25,6^{\circ} \mathrm{C}$, respectivamente e estação seca de junho a outubro (Ribeiro, 1976). Os dados do Instituto Nacional de Meteorologia - INMET referentes aos anos de 1961 a 1990 apontam temperatura máxima de $31,5^{\circ} \mathrm{C}$ e mínima de $23,2^{\circ} \mathrm{C}$, média de $26,7^{\circ} \mathrm{C}$, precipitação de $2.291,8 \mathrm{~mm}$ e umidade relativa do ar de $83 \%$.

Para descrição da morfologia floral foi realizado acompanhamento fenológico das flores no período de novembro de 2002 a outubro de 2003. O material botânico, coletado de sete indivíduos, foi analisado e descrito no Laboratório de Botânica Agroflorestal - LABAF, da Universidade Federal do Amazonas UFAM. Amostras das ráquilas foram fixadas em álcool $70 \%$ para descrição morfológica das flores (pistiladas e estaminadas), bem como do ramo florífero. As inflorescências foram caracterizadas por meio de observaçōes no campo e no laboratório. As descriçōes foram baseadas nas literaturas de Henderson et al. (1995) e Uhl \& Dransfield (1987), utilizando-se microscópio estereoscópio.

As documentaçōes foram feitas por meio de registro fotográfico em microscópio estereoscópio Zeiss com Câmera MC80dx.

A determinação da cor das flores foi feita de acordo com os códigos de cores da tabela de Kornerup \& Wanscher (1961).

As flores pistiladas e estaminadas foram quantificadas para se estimar o número médio por inflorescência e por ráquila. Para tal, foram coletadas amostras de flores contidas em dez ráquilas de sete inflorescências diferentes. $\mathrm{O}$ tamanho das inflorescências foi medido por meio de trena, enquanto o tamanho das ráquilas e flores foram obtidos com auxilio régua e paquímetro.

\section{RESULTADOS E DISCUSSÃO}

A inflorescência de A. aculeatum é envolvida por uma espata que, ao se desenvolver, torna-se intumescida (Figura $1 \mathrm{~b} \mathrm{e} \mathrm{c),}$ podendo durar de 30 a 45 dias até sua abertura, feita através de uma fenda longitudinal. A espata possui a cor preta (5-2F) devido a concentração de espinhos, variando de cinza (5-1B) a castanho (8-4B) até sua abertura. Quando observada no campo, a cor das inflorescências varia de indivíduo para indivíduo, podendo ser creme esverdeado (29-3A), ou cinza (5-1B).

A inflorescência de $A$. aculeatum é pedunculada, interfoliolar e apresenta tamanho médio de $164 \pm 20,3 \mathrm{~cm}$. As flores unissexuadas se dispóem em ráquilas de primeira ordem 
pendulares, tomentosas, cilíndricas, que se inserem em planos diferentes no eixo principal denominado ráquis (Figura $2 \mathrm{~g}$ ). Têm em média $375 \pm 49,5$ ráquilas, com comprimento que pode variar de $18,549,0 \mathrm{~cm}$. Cada ráquila apresenta no seu ponto de inserção na ráquis uma bráctea alongada fibrosa. Foi verificada a presença de acúleos bem finos sobre as ráquilas e flores pistiladas, sendo os de tonalidade branca menores, e os castanhos maiores e mais rígidos.

Ocorre de uma a sete flores pistiladas na base de cada ráquila (média 2,3 $\pm 1,1$ ). Essas flores se localizam na região basal da ráquila e a cada uma unem-se duas flores estaminadas, formando uma "tríade", principal característica, que distingue a subfamília Arecoideae (Uhl \& Dransfield,1987). Podem-se, ainda, encontrar flores estaminadas isoladas ou em pares nessa porção do ramo.

As flores pistiladas têm a forma de copo ou barril. São sésseis, trímeras, actinomorfas, gamossépalas, gamopétalas (Figura 2a f). Cada flor tem na sua base uma bractéola membranosa circular. O ovário é súpero, tricarpelar, unilocular, com um óvulo, apresentando um anel membranoso com seis estaminódios vestigiais na sua base (Figura $2 \mathrm{o}-\mathrm{p}$ ). O estilete é terminal com estigma carnoso e trífido sobressaindo-se à corola. $\mathrm{O}$ cálice e a corola são persistentes.

A parte mediana e apical da ráquila é completamente coberta por flores estaminadas densamente arranjadas na espigueta. Estas por sua vez, apresentam tamanho e forma diferentes das pistiladas,
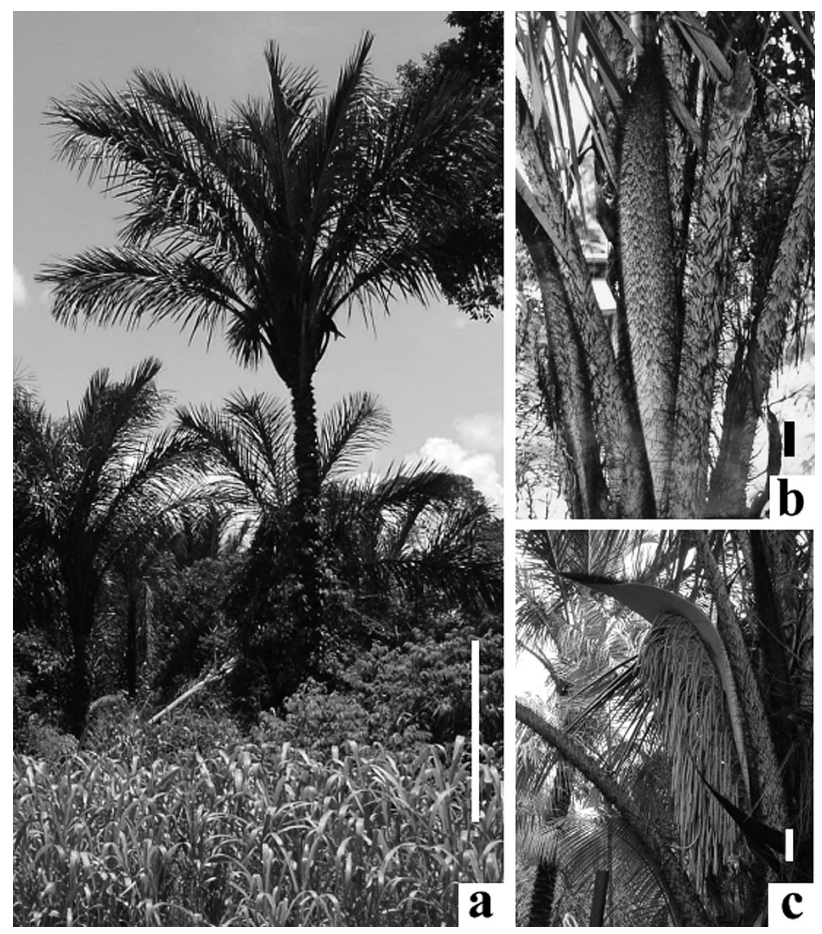

Figura 1 - A. aculeatum. a - Indivíduo adulto, escala $=300 \mathrm{~cm} ; \mathrm{b}$ Inflorescência com espata fechada; $c$ - Inflorescência com espata aberta. Escala $=16,6 \mathrm{~cm}$. sendo menores e mais numerosas. A amplitude do número de flores estaminadas por ráquila é de 309 - 859. O tamanho médio encontrado para espigueta foi de $20,4 \pm 3,8 \mathrm{~cm}$, atingindo quase o dobro do comprimento médio da região basal com 13,8 $\pm 4,0$ $\mathrm{cm}$.

As flores estaminadas são tubiformes, sésseis, trímeras, actinomorfas, gamossépalas, apresentando uma bractéola na base. Possuem seis estames excertos com anteras dorsifixas e deiscência
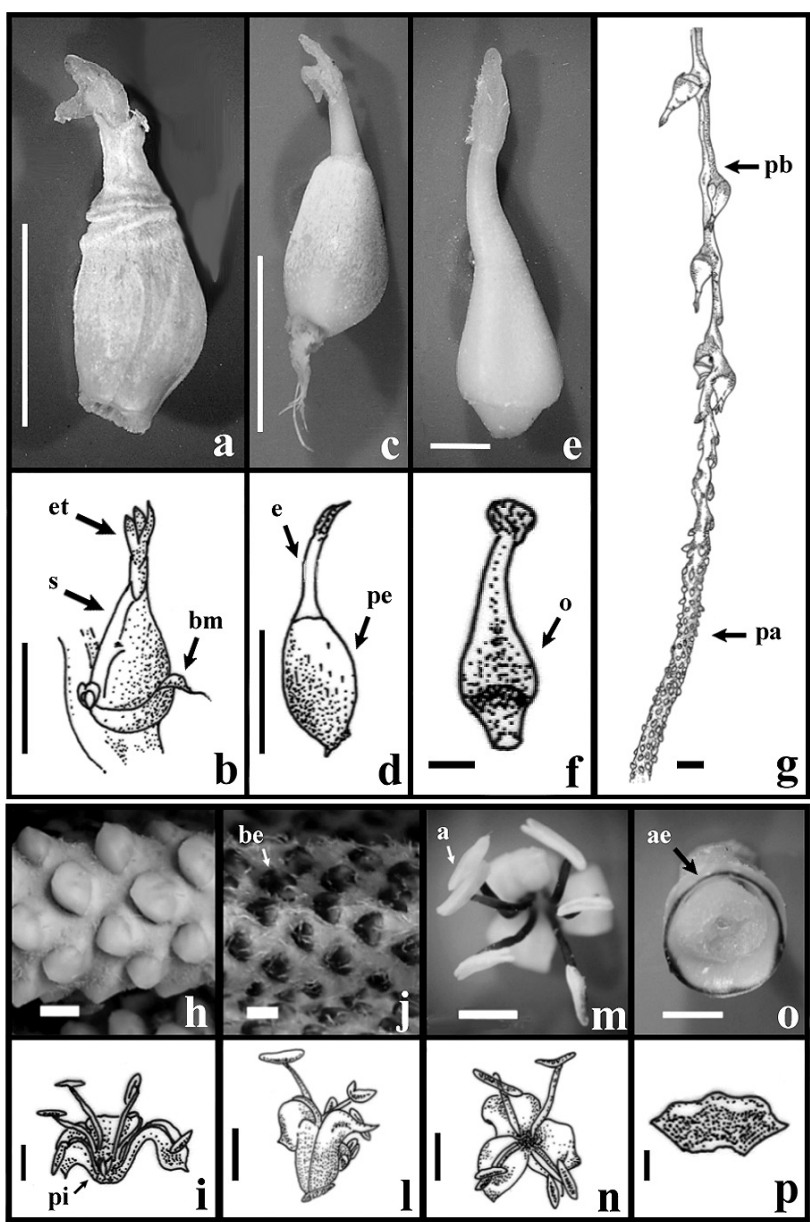

Figura 2 - Morfologia das flores de A. aculeatum. a - Flor pistilada com sépalas; $b$ - Flor pistilada inserida na ráquis mostrando bráctea membranosa basal; c - Flor pistilada com pétalas e sépalas removidas; d - Flor pistilada, escalas $=1 \mathrm{~cm}$; e - Detalhes do pistilo; $f$ - Pistilo, escalas $=0,25 \mathrm{~cm} ; g$ - Ráquila com flores pistiladas basais e botões estaminados, escala $=1$ $\mathrm{cm} ; \mathrm{h}$ - Botões florais com pétalas cor creme; $\mathrm{j}$ - Botões florais com pétalas cor vinho; i - Flor estaminada com pétala removida; I - Vista lateral da flor estaminada, escalas $=0,25 \mathrm{~cm} ; \mathrm{m}$ - Vista frontal da flor estaminada com detalhe das anteras, escala $=0,22 \mathrm{~cm} ; \mathrm{n}$ - Flor estaminada; 0 - Anel com estaminódios vestigiais na base da flor pistilada; $p$ - Anel removido, escalas $=0,25 \mathrm{~cm}$. a = antera; ae = anel estaminodial; be = botão estaminado; $\mathrm{bm}=$ bráctea membranosa; $\mathrm{e}=$ estilete; et $=$ estigma tríido; $0=$ ovário $\mathrm{pa}=$ porção apical; $\mathrm{pb}=$ porção basal; $\mathrm{pe}=$ pétala; $\mathrm{pi}=$ pistilódio; $\mathrm{s}=$ sépala. 
rimosa. Cada flor apresenta um pistilódio trífido. As pétalas ficam recurvadas durante a antese, conforme mostra a figura $2 \mathrm{~m}, \mathrm{i}, \mathrm{le}$ $\mathrm{m}$.

São encontradas flores estaminadas apresentando três padrões de cores: pétalas inteiramente creme $(30-2 \mathrm{~A})$, pétalas inteiramente vinho (13 - 7D) ou com detalhes em vinho (137D). Com o passar dos dias, devido ao envelhecimento das flores, a inflorescência adquire tonalidade marrom. Até o momento, não houve, na literatura, relato de flores estaminadas de $A$ aculeatum com outra cor a não ser a bege, de acordo com a descrição de Santiago et al. (2003). Esses resultados evidenciam variaçôes fenotípicas relativas às flores e inflorescências dentro de uma população. Oliveira et al. (2003) também encontraram para $A$. vulgare Mart. padrão de cores que variam do bege ao violáceo, sendo as flores estaminadas predominantemente beges.

Considerando-se o número médio de flores pistiladas e estaminadas por ráquila e o número de ráquilas por inflorescência, inferiu-se que o número de flores por inflorescências varia entre 434 - 1.424 flores pistiladas e 179.273 - 265.423 flores estaminadas.

A descrição morfológica das flores de $A$. aculeatum da população estudada vem contribuir e complementar as informações apresentadas por Kahn \& Millán (1992), sugerindose que provavelmente existam variaçōes fenotípicas dentro desta população que podem implicar em variedades para a espécie.

Embora $A$. aculeatum esteja inserida no subgênero Pleiogynanthus, segundo (Kahn \& Millán, 1992) por apresentar mais de uma flor pistilada na base da ráquila, esse estudo mostrou que em sete plantas, quatro apresentaram inflorescências com algumas ráquilas da região apical sem nenhuma flor pistilada. Henderson et al. (1995) descreveram a inflorescência de $A$. aculeatum como tendo de duas a quatro flores pistiladas na base de cada ráquila, sendo que foi encontrada de zero a seis flores nas ráquilas na presente pesquisa. Para Uhl \& Dransfield (1987), a variação do número de flores pistiladas formando tríades é de duas a cinco por ráquila.

Características como a presença de brácteas na base de cada ráquila e a organização das flores estaminadas em espiguetas, também são encontradas em outras palmeiras como Mauritia flexuosa L. f., no vale do Acre (De Paula Fernandes, 2001) e $A$. acaule Mart. em Manaus (Araújo, 2005). A existência do disco estaminodial, com seis estaminódios vestigiais na flor pistilada, parece ser marcante para o gênero Astrocaryum, uma vez que $A$. acaule também apresenta tal estrutura nas suas flores (Araújo, 2005).

Estudos mais recentes sobre o gênero Astrocaryum na Amazônia utilizando a taxonomia clássica e análise de DNA (AFLP) mostraram que espécies como A. sciophilum (Miq.) Pulle e A. chambira Burret aparecem geneticamente distantes do subgenero Ayri, ao qual estavam anteriormente inseridas. Essa análise de Kahn \& Second (1999) também presumiram que existe um híbrido de $A$. aculeatum e Astrocaryum jauari Mart., intermediário entre os parentais. Diante da possibilidade de existência de um híbrido e das variaçōes fenotípicas encontradas para as flores na população estudada, sugere-se que sejam realizados estudos de descrição morfológica, reprodutiva e vegetativa para A. aculeatum, com amostras de várias áreas de ocorrência da espécie na Amazônia, bem como estudos genéticos visando obter resultados mais conclusivos a respeito dessas variaçōes.

\section{AGRADECIMENTOS}

À Fundação Botânica Margareth Mee-FBMM pelo apoio financeiro. À Coordenação de Aperfeiçoamento de Pessoal de Nível Superior - CAPES pela bolsa de pós-graduação concedida. Ao Dr. Alexandre Coletto Silva, pela colaboração na composição das imagens.

\section{BIBLIOGRAFIA CITADA}

Araújo, M.G.P. 2005. Morfo-anatomia e desenvolvimento dos frutos e sementes de três espécies da subfamília Arecoideae (Arecaceae). Tese de Doutorado. Instituto Nacional de Pesquisas da Amazônia INPA/Universidade Federal do Amazonas - UFAM. Manaus, Amazonas. 189 pp.

Cavalcante, P.B. 1991. Frutas comestiveis da Amazônia. $3^{\mathrm{a}}$ ed. CEJUP, CNPq. Museu Paraense Emílio Goeldi - Coleção Adolfo Ducke. Belém. 279 pp.

De Paula, Fernandes N.M. 2001. Estratégias da produção de sementes e estabelecimento de plântulas de Mauritia flexuosa L.f. (Arecaceae) no Vale do Acre/Brasil. Instituto Nacional de Pesquisas da Amazônia - INPA/Universidade Federal do Amazonas - UFAM. Manaus, Amazonas. 244 pp.

Gentry, A.H. 1978. Diversidade e regeneração da capoeira do INPA, com referência especial as Bignoniaceae. Acta Amazonica, 8(1): $67-70$.

Henderson, A. 1995. The Palms of the Amazon. Oxford University Press, New York. 362 pp.

Henderson, A.; Galeano, G.; Bernal, R. 1995. Field guide to the palms of the Americas. Princeton University Press, Princepton, New Jersey. 352 pp.

Kahn, F.; Millán, B. 1992. Astrocaryum (Palmae) in Amazonia a preliminary treatment. Bull. Inst. Fr. Etudes Andines, 21(2): 459531.

Kahn, F.; Second, G. 1999. The genus Astrocaryum (Palmae) in Amazonia: Classical taxonomy and DNA analysis (AFLP) In: Henderson, A.; Borchsenius, F. Evolution, Variation, and Classification of palms. 83: 179-184.

Kornerup, A.; Wanscher, J.H. 1961. Taschenlexikon der Farben. Muster-Schmidt Verlag-Zürich-Göttingen. 242 pp.

Lorenzi, H.; Souza, H.M.; Medeiros-Costa, J.T.de. 1996. Palmeiras do Brasil: nativas e exóticas. Nova Odessa, SP. Ed. Plantarum. $306 \mathrm{pp}$. 


\section{ACTA}

Lorenzi, H.; Souza, H.M.; Costa, J.T.M.; Cerqueira, L.S.C.; Ferreira, E. 2004. Palmeiras Brasileiras e Exóticas Cultivadas. Nova Odessa - SP, Ed. Plantarum, 432 pp.

Mendonça, M.S.; Araújo, M.G.P. de. 1999. A semente de Bacaba (Oenocarpus bacaba Mart. - Arecaceae): Aspectos morfológicos. Revista Brasileira de Sementes, 21(1): 122-124.

Miranda, I.P.de A.; Rabelo, A.; Bueno, C.R.; Barbosa, E.M.; Ribeiro, M.N.S. 2001. Frutos da palmeiras da Amazônia. MCT INPA. Manaus. 120 pp.

Oliveira, M.S.P.; Couturier, G.; Beserra, P. 2003. Biologia da polinização palmeira tucumã (Astrocaryum vulgare Mart.) em Belém, Pará, Brasil. Acta botanica Brasilica, 17(3): 343-353.

Prance, G.T. 1975. The history of the INPA capoeira based on ecological studies of Lecythidaceae. Acta Amazonica, 5(3): 261263.

Ribeiro, M.N.G. 1976. Aspectos climatológicos de Manaus. Acta Amazonica, 6 (2): 229-233.
Santiago, F. F.; Miranda, I. P. A.; Rabelo, A.; Moura, J. B. B.; Chaves, L. S. 2003. Estudo da biologia floral de duas espécies de palmeiras de interesse econômico da região amazônica. In: 54 Congresso Nacional de Botânica. Desafios da Botânica Brasileira no Novo Milênio: Inventário, Sistematização, Conservação e Uso da Diversidade Vegetal (CD ROM Resumos). Belém-PA.

Uhl, N.W.; Dransfield, J. 1987. Genera Palmarum. A Classification of Palms Based on the Work of Harold E. Moore, Jr. Allen Press, Lawrence, Kansas. 610 pp.

Recebido em 06/02/2006

Aceito em 20/10/2006 
